\title{
Editorial
}

\section{A Year like No Other}

\section{Meredith Wallace Kazer, PhD, APRN-BC, FAAN \\ Editor-in-Chief}

The spring and summer of 2020 was distinct from anything I've witnessed in over two decades in academia. As the Covid-19 Pandemic swept through the U.S., colleges and universities quickly shifted to online education. We dragged students back from their international educational experiences to ensure their health and safety from the novel Corona Virus. We provided virtual education and student support resources to close out spring semesters. We were saddened that our students spent the final part of their spring semester in remote instruction. We were unable to celebrate graduations in person. We hoped things would improve in summer in response to Phase I mitigation efforts, but they only worsened. Fall planning began in June with the same hopes for improvement. As July and August approached, hopes were diminished. September found some colleges and Universities delaying openings. Others opened and quickly went remote. We continue to watch the numbers and we continue to stay vigilant.

When the Pandemic first hit the U.S. and the national death toll reached as high as 200,000, I remember my shock. How could this happen? As I write this, the death toll from the Covid-19 pandemic is currently 208,054. In the time between my first and final draft of this editorial, the number of U.S. deaths increased by 20,000. The death toll is expected to exceed 400,000 by the end of the calendar year. As a nation, we are grieving the loss of lives from the pandemic, knowing that many additional tragic deaths will follow. The economic impacts of the pandemic contribute additional devastation upon the world. Countless members of our academic communities have suffered and died from the coronavirus disease. Others have cared for friends and relatives who have suffered and died. There are few among us whom have not been profoundly impacted.

I'm a perpetual optimist and fixer. It's unlike me to dwell in difficulty as I do in this editorial. I prefer to acknowledge the state of affairs and move quickly into action. What can I do to fix these national plagues? What is our collective contribution as academic communities? We can do what we do best. As an academic community focused on health and well-being, we can set up systems to ensure the health and safety of our campuses, be they inperson or remote. We can engage with openness to dialogue and curiosity in discussion rather than dismissiveness. We can be humble, not defensive. We can follow science and make data-driven decisions. We can vote. Most importantly, we can and should commit to sustained education and action, in addition to a continual reflection upon and sharing of our positive work with our entire community. Maybe, in doing so, we can make this world a little better than it is right now. 